Pacific Journal of Mathematics

EVERYWHERE DEFINED LINEAR TRANSFORMATIONS 


\title{
EVERYWHERE DEFINED LINEAR TRANSFORMATIONS AFFILIATED WITH RINGS OF OPERATORS
}

\author{
ERnest L. GRIFFin
}

Let $M$ be a ring of operators on a Hilbert space $H$. This paper considers conditions under which an operator $T$ afflliated with $M$ is bounded (or can be unbounded). In particular, we consider operators whose domain is the entire space $H$. We prove: Theorem 3 . If $M$ has no type $I$ factor part, then $T$ is bounded. THEOREM $4 . T$ is bounded if and only if $T$ is bounded on each minimal projection in $M$. THEorem 6 . In order that every linear mapping from $H$ into $H$ which commutes with $M$ be bounded, it is necessary and sufficient that $M$ should contain no minimal projection whose range is an infinite dimensional subspace of $H$. These results were suggested by a theorem of J. R. Ringrose: Theorem 8. If $M=M^{\prime}$ then $T$ is bounded.

In a paper on triangular algebras ([4], Lemma 2.12) J. R. Ringrose encountered the following situation: he was given a linear operator $T$ with domain equal to an entire Hilbert space $H$ and a ring of operators $M$ commuting with $T$. In the case $M=M^{\prime}$ ( $M$ maximal abelian) he was able to show that $T$ had to be bounded. (For the relevant background theory, see $[1,2]$.) The purpose of this paper is to consider other types of rings of operators commuting with $T$ and conditions under which $T$ can be unbounded.

2. Since the projections in $M$ commute with $T$, the ranges of these projections are invariant under $T$; and consequently operators are induced thereby on such subspaces. We begin by considering orthogonal families of such operators.

LEMMA 1. If $\left\{E_{\gamma} \mid \gamma \in \Gamma\right\}$ is an orthogonal family of projections in $M$, then the norms $\left\{\left\|T E_{\gamma}\right\| \mid \gamma \in \Gamma\right\}$ are almost uniformly bounded; that is, there exists a finite subset $\Gamma_{0}$ of $\Gamma$ and a positive number $b$ such that $\left\|T E_{\gamma}\right\| \leqq b$ for $\gamma \in \Gamma-\Gamma_{0}$.

Proof. Assume lemma false. We first choose a $E_{\gamma_{1}}$ such that $\left\|T E_{\gamma_{1}}\right\|>1$. (If $\left\|T E_{\gamma}\right\| \leqq 1$ for all $\gamma \in \Gamma$; then $\Gamma_{0}=$ null set, $b=1$ fulfills the lemma.) Now assume for a positive integer $n$ that $\left\{E_{\gamma_{k}} \mid k=1,2,3, \cdots, n\right\}$ have been chosen so that $\left\|T E_{\gamma_{k}}\right\|>k$ for each $k$. If $\left\|T E_{\gamma}\right\| \leqq n+1$ for $\gamma \in \Gamma-\left\{\gamma_{k} \mid k=1,2,3, \cdots, n\right)$, then $b=n+1$ leads to the conclusion of the lemma. Thus we can pick 
a $\gamma_{n+1}$ such that $\left\|T E_{\gamma_{n+1}}\right\|>n+1$. Finally, our induction produces a sequence $E_{\gamma_{k}}$ with $\left\|T E_{\gamma_{k}}\right\|>k$ for all integers $k$.

Next, select $x_{k}$ in $E_{k} H$ such that $\left\|x_{k}\right\|=1$ and $\left\|T x_{k}\right\|=\left\|T E_{\gamma_{k}} x_{k}\right\| \geqq k$ for all $k$, using $\left\|T E_{k}\right\|>k$. Let $y_{n}=\sum_{k=1}^{n} x_{k} / k$. Now, since

$$
\left\|y_{n}\right\|^{2}=\sum_{k=1}^{n} \frac{\left\|x_{k}\right\|^{2}}{k^{2}}=\sum_{k=1}^{n} \frac{1}{k^{2}}<\infty \text {. }
$$

$y_{n}$ converges to a vector $y$ in $H$. Clearly $y_{n} \in\left(\sum_{k=1}^{n} E_{\gamma_{k}}\right) H$ and $y$ $y_{n} \in\left(\sum_{k>n} E_{\gamma_{k}}\right) H$. Since these two subspaces are orthogonal and invariant under $T, T y_{n}$ is orthogonal to $T\left(y-y_{n}\right)$ for each integer $n$. But, by Bessel's inequality

$$
\|T y\|^{2} \geqq\left\|T y_{n}\right\|^{2}=\left\|\sum_{k=1}^{n} \frac{T E_{\gamma_{k}} x_{k}}{k}\right\|^{2}=\sum_{k=1}^{n} \frac{\left\|T E_{\gamma_{k}} x_{k}\right\|^{2}}{k^{2}} \geqq \sum_{k=1}^{n} \frac{k^{2}}{k^{2}}=n .
$$

The contradiction $\|T y\|^{2} \geqq n$ for all $n$ completes the proof of the lemma.

COROLLARY 1. If all the $T E_{\gamma}$ are bounded, then the set $\left\{\left\|T E_{\gamma}\right\| \mid \gamma \in \Gamma\right\}$ is uniformly bounded.

Corollary 2. If $\Gamma$ is infinite, at least one of the $T E_{\gamma}$ is bounded.

LEMma 2. If the $\left\{E_{\gamma} \mid \gamma \in \Gamma\right\}$ of Lemma 1 is such that the $\left\{\left\|T E_{\gamma}\right\| \mid \gamma \in \Gamma\right\}$ are uniformly bounded by the number $b>0$, then $\left\|T\left(\Sigma_{\gamma} E_{\gamma}\right)\right\| \leqq b$.

Proof. For $x$ in $H,\left\|T\left(\Sigma_{\gamma} E_{\gamma}\right) x\right\|^{2}=\left\|\left(\Sigma_{\gamma} E_{\gamma}\right) T x\right\|^{2}=\Sigma_{\gamma}\left\|E_{\gamma} T x\right\|^{2}=$ $\Sigma_{\gamma}\left\|\left(T E_{\gamma}\right) E_{\gamma} x\right\|^{2} \leqq \Sigma_{\gamma} b^{2}\left\|E_{\gamma} x\right\|^{2} \leqq b^{2}\|x\|^{2}$.

LEMMA 3. If $E, F$ are projections which are equivalent relative to $M$; then $\|T E\|=\|T F\|$.

Proof. Let $V$ be a partial isometry in $M$ with initial domain $E H$ and terminal domain $F H_{\text {. (or }} V^{*} V=E, V V^{*}=F$.) Now $V(T E) V^{*}=$ $T V E V^{*}=T V V^{*} V V^{*}=T F^{2}=T F$ and $\|T F\|=\left\|V(T E) V^{*}\right\| \leqq\|V\| \cdot$ $\|T E\| \cdot\left\|V^{*}\right\| \leqq\|T E\|$. Interchanging $V-V^{*}$ yields $\|T E\| \leqq\|T F\|$ and completes the proof.

3. Definition 1. Let $T$ be a everywhere defined operator on a Hilbert space. $T$ is said to be totally unbounded with respect to the ring of operators $M$ if $T$ commutes with the elements of $M$ and $T E$ is unbounded for each nonzero projection $E$ in $M$. 
THEOREM 1. Let $T$ be a everywhere defined operator on $H$ commuting with a ring of operators $M$. If $T$ is unbounded then there exists a central projection $P$ in $M$ such that $P T$ is bounded and $P^{\perp} T$ is totally unbounded with respect to $M P^{\perp}$.

Proof. If $T$ totally unbounded with respect to $M$, then the projection 0 qualifies as our $P$. Thus we may restrict ourselves to the cases in which nonzero projections $E$ exist in $M$ such that $T E$ is bounded.

Choose a maximal collection $\left\{E_{\gamma} \mid \gamma \in \Gamma\right\}$ of nonzero orthogonal projections of $M$ with each $T E_{\gamma}$ bounded. It then follows from Corollary 1 to Lemma 1 that the $\left\{\left\|T E_{\gamma}\right\| \mid \gamma \in \Gamma\right\}$ are uniformly bounded. Then, Lemma 2 shows that $T$ is bounded on $\Sigma_{\gamma \in \Gamma} E_{\gamma}$.

Now, let $P=\Sigma_{\gamma \in \Gamma} E_{\gamma}$. Obviously $T P$ is bounded; and if $T E$ is bounded for $0 \neq E \leqq P^{\perp}, E \in M$, then $E$ could be added to our maximal collection $\left\{E_{\gamma} \mid \gamma \in \Gamma\right\}$. Thus, it only remains to prove that $P$ is central.

Let $Q$ be the central cover of $P$ in $M$. If $Q-P \neq 0$, apply the projection comparison lemma ([1], p. 227, Lemma 1$)$ to $(Q-P, P)$ to get two nonzero projections $E, F$ in $M$ such that $E \leqq P, F \leqq Q-P$ and $E \sim F$. But Lemma 3 shows that $\|T F\|=\|T E\|<\infty$ contradicting the first part of the proof of this lemma. Thus $Q-P=0$ and $P$ is central in $M$.

4. It is clear from Theorem 1 that the problem of classifying everywhere defined unbounded operators commuting with rings of operators can be reduced to the study of totally unbounded operators. Thus we consider the following theorem.

THEOREM 2. If $T$ is totally unbounded with respect to the ring $M$, then $M$ is a finite direct sum of finite factors of type $I$. In each factor direct summand, $M^{\prime}$ is an infinite factor of type $I$.

Proof. Let $E$ be any nonzero projection in $M$ and assume that $E$ does not contain a minimal projection of $M$. If so, then there exists a nonzero projection $E_{1}$ in $M$ such that $E_{1} \lesseqgtr E$ and $E_{1}$ not minimal. Similarly an $E_{2}(\neq 0)$ in $M$ with $E_{2} ફ E_{1}$ and $E_{2}$ not minimal exists. Continuing in this fashion by induction we obtain a decreasing sequence of projections $\left\{E_{k} \mid k=1,2,3, \cdots\right\}$ in $M$. But now $\left\{F_{k}=\right.$ $\left.E_{k}-E_{k+1} \mid k=1, \cdots\right\}$ is an infinite set of orthogonal projections in $M$ and Corollary 2 to Lemma 1 yields a projection $F_{s}$ on which $T F_{s}$ is bounded-contradicting total unboundedness. Thus each nonzero projection in $M$ contains a minimal projection. 
Now pick a maximal family $\left\{F_{\gamma} \mid \gamma \in \Gamma\right\}$ of orthogonal minimal projections in $M$. Clearly, $\Gamma$ is finite. If $\Sigma_{\gamma \in \Gamma} F_{\gamma}=P \neq I$, then $P^{\perp}$ contains a minimal projection $F$ orthogonal to the $F_{\gamma}$ contradicting maximality of $\left\{F_{\gamma} \mid \gamma \in I\right\}$.

Thus $I=\Sigma_{\gamma \in \Gamma} F_{\gamma}=\Sigma_{l k} \in_{\kappa} P_{\kappa}$, where the $P_{k}$ are the central projections obtained by adding up the (finite) families of equivalent minimal projections in $\Gamma$. It is clear that $M=\Sigma_{k} M P_{k}$ is a direct sum decomposition of $M$ into a finite number of finite factors of type $I$. It is also clear that $M^{\prime}=\Sigma_{k} M^{\prime} P_{k}$ is a direct sum decomposition of $M^{\prime}$ into factors of type I. Further, if one of the $M^{\prime} P_{k}$ is of finite type, the fact that $M P_{k}$ is a finite factor of type I leads to $P_{k} H$ being finite dimensional in $H$ and to $T P_{k}$ being necessarily bounded-contradicting total unboundedness of $T$. Hence each $M^{\prime} P_{k}$ is of infinite type I.

The next theorems are corollaries of Theorems 1 and 2. In each, $T$ is everywhere defined and commutes with a ring of operators $M$.

THEOREM 3. If $M$ has no type I factor part, then $T$ is bounded.

THEOREM 4. T is bounded if and only if it is bounded on each minimal projection in $M$.

THEOREM 5. If the coupling operator for the pair of rings $M^{\prime}$, $M$ is essentially bounded then $T$ is bounded. In fact, $M^{\prime}=\{T: H$ into $H \mid T$ linear and commutes with $M$ \}. (see [2], p. 497, Def. 3.2).

THEOREM 6. In order that every linear mapping from $H$ into $H$ which commutes with $M$ be bounded, it is necessary and sufficient that the finite central part of $M$ should contain no minimal projection whose range is an infinite subspace of $H$.

Proof. Sufficiency is clear. In case a minimal projection $E$ has infinite dimension in $H$, let an unbounded operator with domain equal to $E H$ be selected leaving $E H$ invariant; and extend it to an orthogonal family of minimal projections (whose union is the central cover of $E$ ) by means of partial isometries. On parts orthogonal to the central cover define the mapping to be zero. If $T$ is this operator, it is clear that $T$ is unbounded, everywhere defined, and commutes with $M-$ thus contradicting our hypothesis.

TheOREM 7. If $M^{\prime}$ is finite, then $T$ is bounded.

Theorem 8. (See Ringrose [4], Lemma 2.12) If $M=M^{\prime}, T$ is bounded. (This is a corollary to Theorems 5 and 7.)

5. We now consider the well-known theorem: If $T$ is an every- 
where defined linear operator on $H$, then $T$ is bounded if and only if $T$ is closed. This is usually deduced from the closed graph theorem, but we shall give here a proof along the lines of the first sections of this paper.

By a theorem of von Neumann ([3]) a closed operator with dense domain $\mathscr{D}_{T}$ has a polar decomposition $V S$ with $S \geqq 0, \mathscr{D}_{S}=$ $\mathscr{D}_{T},\|V\| \leqq 1$, so that it suffices to restrict ourselves to the case $T \geqq 0$. We assume $T$ unbounded.

Since $T$ is now self-adjoint, we apply the spectral theorem to obtain a sequence of orthogonal projections $\left\{E_{k} \in M \mid k=1,2, \cdots\right\}(M=$ ring generated by spectral family of $T$ ) with $\left\|T E_{k}\right\|$ unbounded. But now the reasoning of Lemma 1 proves that $T$ cannot be defined on all of $H$.

\section{References}

1. J. Dixmier, Les algèbres d'opérateurs dans l'espace hilbertien, Paris, 1957.

2. E. L. Griffin, Some contributions to the theory of rings of operators, Trans. Amer. Math. Soc. 75 (1953), 471-504.

3. J. von Neumann, Über adjungierte Funktionaloperatoren, Ann. of Math, 33 (1932), 294-310.

4. J. R. Ringrose, On some algebras of operators II (unpublished).

Received April 16, 1965. This research partially supported by NSF GP 4059.

University of PennsylVania 



\section{PACIFIC JOURNAL OF MATHEMATICS}

\section{EDITORS}

\author{
H. SAMELSON, \\ Stanford University \\ Stanford, California \\ R. M. BLUMENTHAL \\ University of Washington \\ Seattle, Washington 98105
}

\author{
*J. DugundJI \\ University of Southern California \\ Los Angeles, California 90007 \\ RICHARD ARENS \\ University of California \\ Los Angeles, California 90024
}

\section{ASSOCIATE EDITORS}
E. F. BECKENBACH
B. H. NeUmanN
F. WOLF
K. YOSIDA

\section{SUPPORTING INSTITUTIONS}

\author{
UNIVERSITY OF BRITISH COLUMBIA \\ CALIFORNIA INSTITUTE OF TECHNOLOGY \\ UNIVERSITY OF CALIFORNIA \\ MONTANA STATE UNIVERSITY \\ UNIVERSITY OF NEVADA \\ NEW MEXICO STATE UNIVERSITY \\ OREGON STATE UNIVERSITY \\ UNIVERSITY OF OREGON \\ OSAKA UNIVERSITY \\ UNIVERSITY OF SOUTHERN CALIFORNIA
}

\author{
STANFORD UNIVERSITY \\ UNIVERSITY OF TOKYO \\ UNIVERSITY OF UTAH \\ WASHINGTON STATE UNIVERSITY \\ UNIVERSITY OF WASHINGTON \\ * * * \\ AMERICAN MATHEMATICAL SOCIETY \\ CHEVRON RESEARCH CORPORATION \\ TRW SYSTEMS \\ NAVAL ORDNANCE TEST STATION
}

Mathematical papers intended for publication in the Pacific Journal of Mathematics should be typewritten (double spaced). The first paragraph or two must be capable of being used separately as a synopsis of the entire paper. It should not contain references to the bibliography. Manuscripts may be sent to any one of the four editors. All other communications to the editors should be addressed to the managing editor, Richard Arens at the University of California, Los Angeles, California 90024 .

50 reprints per author of each article are furnished free of charge; additional copies may be obtained at cost in multiples of 50 .

The Pacific Journal of Mathematics is published monthly. Effective with Volume 16 the price per volume (3 numbers) is $\$ 8.00$; single issues, $\$ 3.00$. Special price for current issues to individual faculty members of supporting institutions and to individual members of the American Mathematical Society: $\$ 4.00$ per volume; single issues $\$ 1.50$. Back numbers are available.

Subscriptions, orders for back numbers, and changes of address should be sent to Pacific Journal of Mathematics, 103 Highland Boulevard, Berkeley 8, California.

Printed at Kokusai Bunken Insatsusha (International Academic Printing Co., Ltd.), No. 6, 2-chome, Fujimi-cho, Chiyoda-ku, Tokyo, Japan.

PUBLISHED BY PACIFIC JOURNAL OF MATHEMATICS, A NON-PROFIT CORPORATION

The Supporting Institutions listed above contribute to the cost of publication of this Journal, but they are not owners or publishers and have no responsibility for its content or policies.

* Paul A. White, Acting Editor until J. Dugundji returns. 


\section{Pacific Journal of Mathematics}

\section{Vol. 18, No. 3 \\ May, 1966}

William George Bade and Philip C. Curtis, Jr., Embedding theorems for commutative Banach algebras .......................... 391

Wilfred Eaton Barnes, On the $\Gamma$-rings of Nobusawa ................. 411

J. D. Brooks, Second order dissipative operators ................ 423

Selwyn Ross Caradus, Operators with finite ascent and descent ........ 437

Earl A. Coddington and Anton Zettl, Hermitian and anti-hermitian properties of Green's matrices .......................... 451

Robert Arnold Di Paola, On sets represented by the same formula in distinct consistent axiomatizable Rosser theories ................... 455

Mary Rodriguez Embry, Conditions implying normality in Hilbert space ...........................................

Garth Ian Gaudry, Quasimeasures and operators commuting with convolution ................................... 461

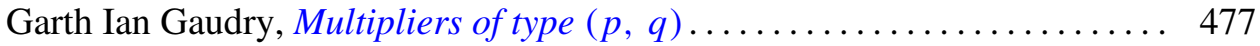

Ernest Lyle Griffin, Jr., Everywhere defined linear transformations affiliated with rings of operators .................................. 489

Philip Hartman, On the bounded slope condition ................ 495

David Wilson Henderson, Relative general position ................ 513

William Branham Jones, Duality and types of completeness in locally

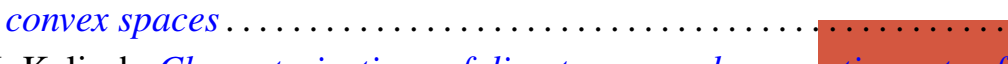

G. K. Kalisch, Characterizations of direct sums and commuting sets of Volterra operators....

Ottmar Loos, Über eine Beziehung zwischen Malcev-Algebren und Lietripelsystemen

Ronson Joseph Warne, A class of bisimple inverse semigroups . . . 